\title{
MIR659 Gene
}

National Cancer Institute

\section{Source}

National Cancer Institute. MIR659 Gene. NCI Thesaurus. Code C81822.

This gene is involved in the regulation of gene expression. While it has no known role in oncogenesis, MIR659 plays a role in the development of frontotemporal dementia. 